\title{
Modeling of Total Cases due to COVID-19 and its Impact in India
}

\author{
Kishor Kulkarni $^{1} \cdot$ Antara Kulkarni $^{2} \cdot$ Naziya Sultana Shaikh $^{3} \cdot$ Siraj Sayyed $^{1}$ (1)
}

Received: 19 May 2020/Accepted: 3 February 2021 / Published online: 16 February 2021

(C) The Institution of Engineers (India) 2021

\begin{abstract}
This research paper focuses on the modeling of total cases due to COVID-19 and the critical assessment of socioeconomic impact on India. The data set considered for the present analysis is from December 31, 2019 to May 16, 2020 for training and testing of developed regression model. Least-square approximation of linear regression technique is applied to estimate the total cases of COVID19. Three variables, viz. daily new cases, total deaths and daily new deaths, were considered for development of correlations. In the present study, seven correlations are developed as a function of single variable, two variables and three variables with accuracy $\left(\mathrm{R}^{2}\right)$ ranging from 85.71 to $99.95 \%$. The paper also highlights the socioeconomic impact of COVID 19 on different sector, challenges and remedies for improving the GDP of the country.
\end{abstract}

Keywords Coronavirus · COVID-19 · Epidemics ·

Pandemics $\cdot$ Modeling $\cdot$ Socioeconomic impact

$\begin{array}{ll}\text { Abbreviations } \\ \% & \text { Percentage } \\ \text { AD } & \text { Anno Domini } \\ \text { BC } & \text { Before Christ } \\ \text { GDP } & \text { Gross domestic products }\end{array}$

Siraj Sayyed

lucky.sartaj@gmail.com

1 Department of Mechanical Engineering, Maharashtra Institute of Technology, Aurangabad, Maharashtra 431010, India

2 Department of MBA, Maharashtra Institute of Technology, Aurangabad, Maharashtra 431010, India

3 Department of CSIT, Dr. Babasaheb Ambedkar Marathwada University, Aurangabad, Maharashtra 431004, India

\begin{tabular}{|c|c|}
\hline IMF & International monitory fund \\
\hline $\mathrm{K}$ & Numbers in thousands \\
\hline MERs & Middle East respiratory syndrome \\
\hline PHEIC & $\begin{array}{l}\text { Public health emergency of international } \\
\text { concern }\end{array}$ \\
\hline $\mathrm{R}^{2}$ & Carl Pearson coefficient \\
\hline SARs & Severe acute respiratory syndrome \\
\hline WHO & World health organization \\
\hline TDS & Tax deducted at source \\
\hline TCS & Tax collected at source \\
\hline MSMEs & $\begin{array}{l}\text { Ministry of micro, small \& medium } \\
\text { enterprises }\end{array}$ \\
\hline NBFs & Non-banking finance companies \\
\hline HFCs & Housing finance companies \\
\hline MFIs & Merchandise exports from India scheme \\
\hline CLSS-MIG & $\begin{array}{l}\text { Credit-linked subsidy scheme (CLSS) for } \\
\text { middle-income groups (MIG) }\end{array}$ \\
\hline $\mathrm{KCC}$ & Kisan Credit Card \\
\hline MGNREGS & $\begin{array}{l}\text { Mahatma Gandhi National } \\
\text { Employment Guarantee Act }\end{array}$ \\
\hline
\end{tabular}

\section{Introduction}

In nineteenth century, the coronavirus has been primarily associated with non-severe respiratory infections in human beings. Afterward, three different types of coronavirus have combined and widespread across the several countries [1-3]. At the beginning of the twentieth century, the severe acute respiratory syndrome (SAR) caused by coronavirus was diagnosed in China and spread in 29 countries with 8096 confirmed cases and 774 deaths [3-6]. In September 2012, the first case of Middle East respiratory syndrome 
Table 1 Chronological history of worse epidemics and pandemics [31]

\begin{tabular}{|c|c|c|c|}
\hline Name of epidemic and pandemic & Year & No. of died & Place of origin/existence observed \\
\hline COVID-19 Pandemic & 2019-2020 & $\begin{array}{l}3,07,146 \text { died, } \\
46,03,043 \text { affected and 17,39,164 recovered } \\
\text { in the world }\end{array}$ & China \\
\hline $\begin{array}{l}\text { ZIKA virus epidemic (spreads through } \\
\text { mosquitos) }\end{array}$ & 2015 & - & South and Central America \\
\hline $\begin{array}{l}\text { West African EBOLA epidemic virus } \\
\text { originated in bats }\end{array}$ & 2014-2016 & 11,325 died and 28,600 affected & $\begin{array}{l}\text { Republic of Sudan in } 1976 \text { and after } \\
\text { in West Africa }\end{array}$ \\
\hline H1N1 Swine flu & 2009-2010 & $5,75,400$ died and 1.4 Billion affected & Mexico \\
\hline $\begin{array}{l}\text { AIDS Pandemic (HIV virus that causes } \\
\text { AIDS) }\end{array}$ & 1981 & Around 35 Million & West Africa \\
\hline Asian flu (blend of avian flu) & $1957-1958$ & 1.1 Million in World and $1,16,000$ in USA & China \\
\hline $\begin{array}{l}\text { Spanish flu (experienced during World } \\
\text { War-I) }\end{array}$ & $1918-1920$ & 1/5th of 500 Million from North Poll & - \\
\hline American polio epidemic (affect children) & 1916 & $6,000(27,000$ cases reported $)$ & New York City \\
\hline Flu pandemic & $1889-1890$ & $1,00,000$ (in 5 weeks) & Russia \\
\hline Philadelphia yellow fever epidemic & 1793 & 5,000 & Philadelphia \\
\hline Russian plague & $1770-1772$ & $1,00,000$ & Moscow \\
\hline Great plague of Marseille & $1720-1723$ & $1,00,000(30 \%$ Population of Marseille) & France \\
\hline Great of plague of London & $1665-1666$ & $1,00,000$ ( $15 \%$ Population of London) & London Europe \\
\hline American plague & $\begin{array}{l}\text { Sixteenth } \\
\text { century }\end{array}$ & $90 \%$ of western hemisphere & Europe and America \\
\hline Cocoliztli epidemic & $1545-1548$ & 15 Million & Mexico and Central America \\
\hline The black death & $1346-1353$ & Half of Europe population & Travel from Asia to Europe \\
\hline Plague of Justinian & $541-542 \mathrm{AD}$ & $10 \%$ of total world & Byzantine Empire of Europe \\
\hline Plague of Cyprian & $250-271 \mathrm{AD}$ & 5000 (in a day) & Tunisia (Rome) \\
\hline Antonine plague & $165-180 \mathrm{AD}$ & $5,00,000$ & Rome \\
\hline Plague of Athens & $430 \mathrm{BC}$ & $1,00,000$ & Athens \\
\hline Circa & $3000 \mathrm{BC}$ & - & China \\
\hline
\end{tabular}

(MERs) coronavirus was reported with 2458 confirmed cases and 848 deaths in 27 countries [7-10].

In December 2019, a new coronavirus was isolated in patients related to a fish market in the city of Wuhan, Hubei Provence of China. This coronavirus named SARs-CoV-2 caused an epidemic in that city that has spread rapidly in the world, possibly the largest pandemic after the Spanish flu [11-13]. As the numbers of patients of pneumonia were increasingly tremendously in the Wuhan, the municipal health commission reported a cluster of cases of pneumonia while considering it as an epidemic healthcare issue which arises from pneumonia [14-16]. A novel coronavirus was eventually identified. Due to human-to-human transmission, the total cases of coronavirus in the world are around 4,621,409 on May 16, 2020 and more than 75\% of total cases of the world shared by these countries with their percentage sharing as USA (32.12\%), Spain (5.94\%), Russia (5.69\%), UK (5.12\%), Italy (4.84\%), Brazil $(4.72 \%)$, France $(3.88 \%)$, Germany (3.80\%), Turkey $(3.17 \%)$, Iran $(2.52 \%)$, India $(1.86 \%)$ and China $(1.79 \%)$
[16]. Total twenty worse epidemics and pandemics were studied under the critical assessment and enlisted in chronological order in Table 1.

WHO issued worldwide health emergency, indicating that SARs-CoV-2 is of urgent global concerned and estimated that reproduction factor $\left(\mathrm{R}_{0}\right)$ as 2.7 . WHO time to time had performed its task during the critical situation and declared public health emergency of international concern (PHEIC) sixth time after the international health regulations came into existence in 2005. On January 30, 2020, WHO reported 7818 total confirmed cases worldwide with majority of these in China and 82 cases reported in 18 countries across the globe. Figure 1 illustrates the details of time-line plan of WHOs from December 31, 2019 to March 18, 2020. Presently, an international clinical trial is generating data from all medical organizations including WHO and researchers are collecting data on coronavirus throughout the world to find the most effective treatments for COVID-19 [16-18]. 


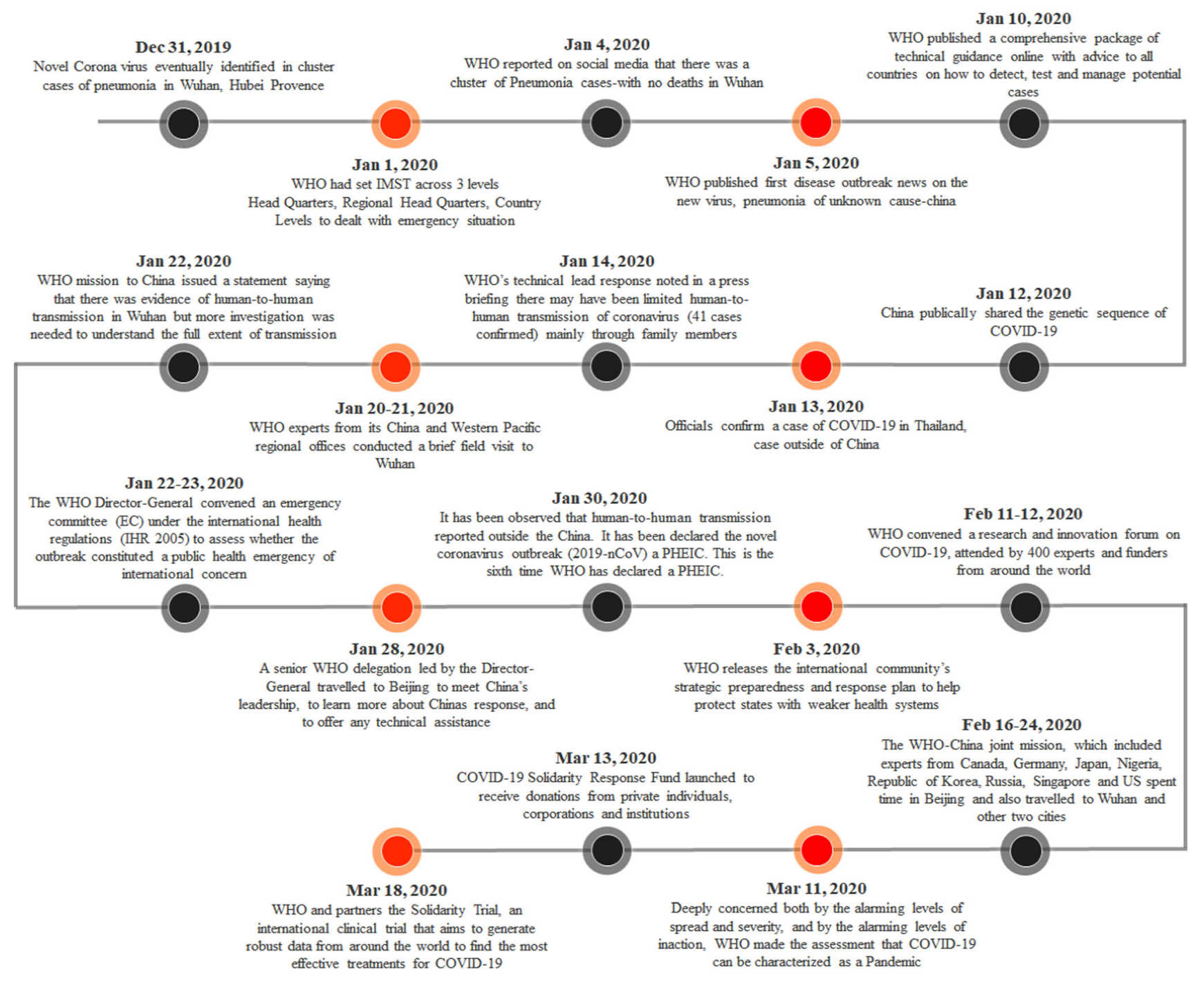

Fig. 1 WHO's time line of COVID-19 [16]

Numerous statistical techniques have gained momentum and are playing important role in the epidemiological data analysis. Statistical technique also can be used to develop standard mortality models like machine learning (ML) [19], artificial neural network (ANN) [20], probabilistic neural network (PNN) [21], Gaussian process for regression (GRNN) [22], auto-regressive integrated moving average (ARIMA) [23] and dynamic modeling [24]. WHO has given some guidelines and recommendations for handling of coronavirus patients. As per the recommendations, Equation A is used to calculate the active cases confirmed and affected by corona virus,

ActiveCases $=$ TotalCases - TotalDeaths - Recovered

where total cases can be calculated as the addition of confirmed positive, presumptive and suspect or probable cases. Total deaths can be calculated as cumulative number of deaths among detected cases. The recovered can be calculated as count of total patients discharged from hospitals, but here in recovered cases, some of the consequences were observed as imperfection in data submission from state to country level or local to national levels and vice versa. To calculate the recovered cases, the WHO recommends the following criteria of [symptoms resolve +2 negative tests within $24 \mathrm{~h}$ ] or [symptoms resolve + additional 14 days], but this is only recommendations [16]. In line with the relevant literature, the present work aimed to propose regression correlations for predicting total cases of COVID-19. The result of the study may facilitate the public health officials of the Indian government for prevention and control measures of COVID-19. 
Fig. 2 Countries with their actual and projected GDP's $[25,26]$

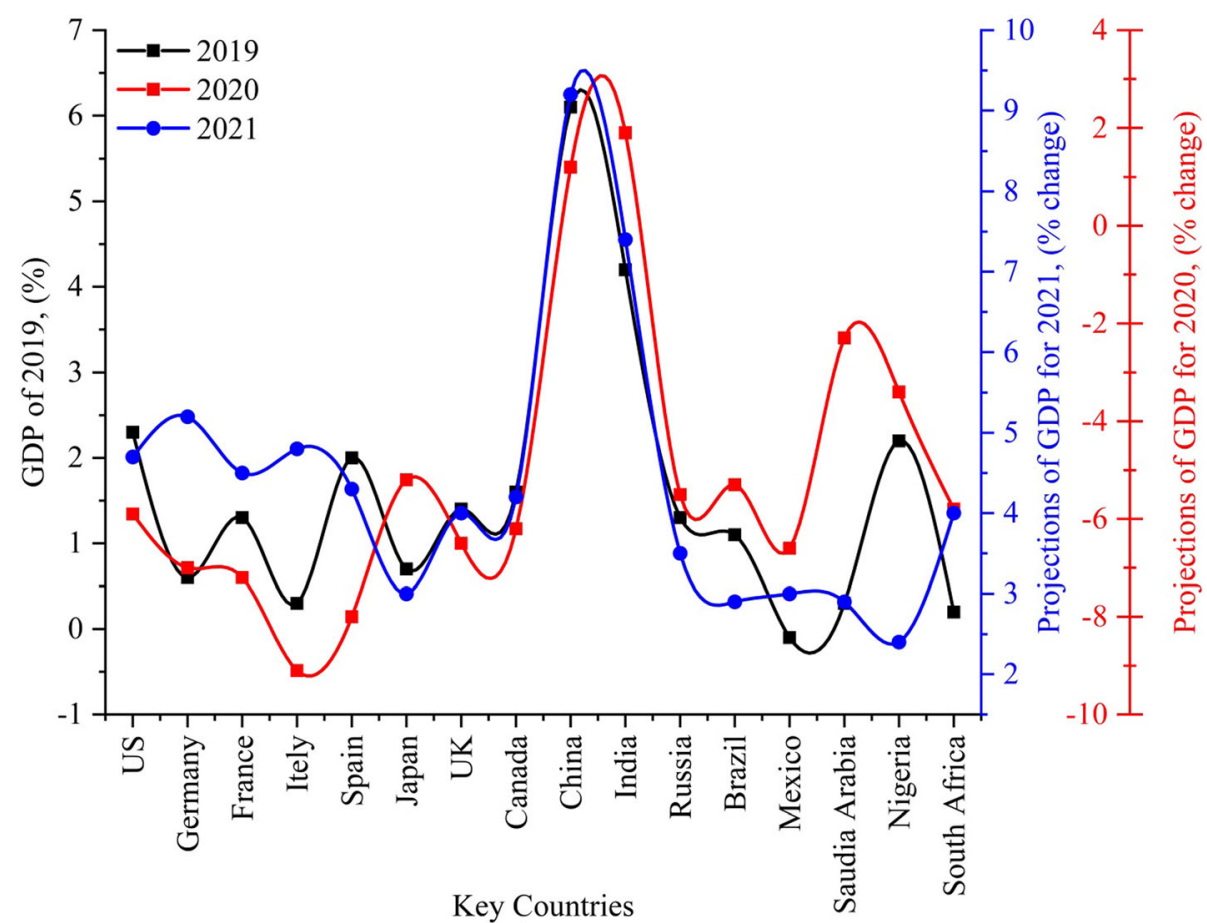

Fig. 3 Actual values of active cases and deaths due to COVID19 [29]

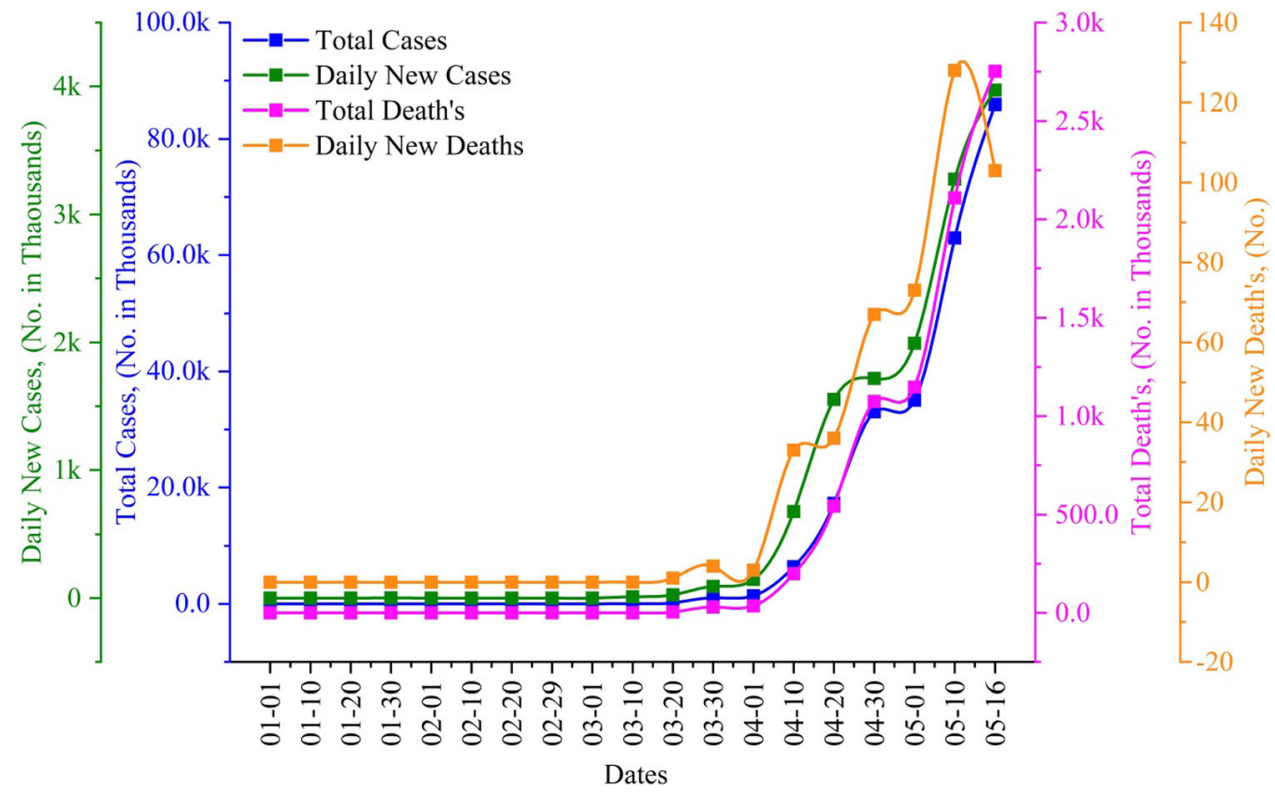

\section{Social Impact Due to COVID-19}

The COVID-19 pandemic affected the educational systems such as schools, colleges and universities worldwide due to its widespread. According to the UNESCO report published on 25 March 2020, around 165 out of 195 countries of the world had closed educational systems due to COVID-19. Because of widespread of COVID-19, an individual with low income suffered mostly and die quickly. It has been observed that the COVID-19 spreads very quickly in crowded residential, markets and workers in low skill jobs $[3,7,8]$.

\section{Economic Impact Due to COVID-19}

WHO declared COVID-19 as a pandemic in January 2020, and it has spread in the worldwide as like wildfire. In the initial stage, most of the countries were taking COVID-19 as a cluster effect of pneumonia, but its adverse effect was 
Table 2 Constants of Regression equation

\begin{tabular}{lccccc}
\hline Constant & Daily new cases & Total death's & Daily new death's & $\mathrm{R}^{2}$ value & Equation No \\
\hline-1062 & 17.554 & & & 95.42 & 3 \\
109.8 & & 30.5211 & & 99.94 & 4 \\
-225 & & 506.5 & 85.71 & 5 \\
126.0 & 30.815 & & 99.94 & 6 \\
-1035 & -0.177 & & -92.7 & 95.64 & 7 \\
152.5 & 20.48 & 31.179 & -12.68 & 99.95 & 8 \\
122.0 & 30.564 & 0.584 & -19.54 & 99.95 & 9 \\
\hline
\end{tabular}

observed in human-to-human transmission. Many of the countries have spent money on the development of medical infrastructures and medicines related to COVID-19. Due to pandemic adverse effect, all the countries across the globe suffered GDP loss. According to International Monitory Fund (IMF), world economic outlook report of April 2020, countries like USA, Germany, France, Italy and Spain had GDP loss ranging from -5.9 to $-9.1 \%$, whereas India and China have GDP loss ranging from 1.9 to $1.2 \%$. As per the projection of financial year 2021, all the countries mentioned in Fig. 2 will be coming up in positive GDP $[25,26]$.

\section{Socioeconomic Impact and Challenges}

Understanding the turmoil effect of the economy is of paramount importance due to COVID 19. It is equally important to summarize the socioeconomic effect of various sectors that include primary sector (agriculture, petroleum and oil) basically involved in extraction of raw material, secondary sector (manufacturing industry), tertiary sectors (education, finance sector, health care and pharmaceutical, tourism, hospitality, aviation, real estate, housing, sports, IT, media food, etc.) and other impacts are social impacts (family, society, etc.). Few of the challenges in front of Indian government are building of medical care facility at macro and micro-level, continuity in supply chain management in commodities, effective utilization of resources, sanitization in containment zone and other areas and issue associated with migrant workers.

On March 25, government invoked Disaster Mitigation Act 2005 and imposed national lockdown and extended it in phases, cancellation of flights at domestic and international level, suspension of train, bus and metro services, sealing of state borders, dedicated COVID-19 quarantine sites, extension of certain compliance deadlines, launching of other IT application like Aarogya Setu App. Recently, government of India has declared rupees 20 lakh crore relief package to boost different sectors such as small/ medium enterprises including MSMEs, NBFs/HFCs/MFIs also reduced the TDS and TCS rates, free food grain supply to migrant workers for 2 months, special credit facility to street vendors, housing CLSS-MIG, additional credit through KCC, Agri-infrastructure fund, additional MGNREGS allocations, etc. The fund was allocated by government of India in five parts in between March 2020 to mid of the May 2020. The Economist Intelligence Unit has

Table 3 Percentile error observed in estimated values from actuals

\begin{tabular}{|c|c|c|c|c|c|c|c|c|}
\hline \multirow[t]{2}{*}{ Date } & \multirow{2}{*}{$\begin{array}{l}\text { Actual } \\
\text { Total cases [27] }\end{array}$} & \multicolumn{7}{|c|}{ Estimated (predicted) total cases from regression correlations } \\
\hline & & 3 & 4 & 5 & 6 & 7 & 8 & 9 \\
\hline 2020-03-20 & 191 & 4.171 & 0.214 & 0.474 & 0.281 & 4.116 & 0.385 & 0.256 \\
\hline 2020-03-30 & 1071 & 0.484 & 0.071 & 0.682 & 0.063 & 0.553 & 0.061 & 0.081 \\
\hline 2020-04-01 & 1397 & 0.074 & 0.157 & 0.073 & 0.156 & 0.200 & 0.137 & 0.128 \\
\hline 2020-04-10 & 6412 & 0.691 & 0.036 & 1.572 & 0.043 & 0.527 & 0.074 & 0.071 \\
\hline 2020-04-20 & 17,265 & 0.517 & 0.034 & 0.043 & 0.039 & 0.589 & 0.037 & 0.020 \\
\hline 2020-04-30 & 33,050 & 0.120 & 0.005 & 0.020 & 0.004 & 0.155 & 0.008 & 0.012 \\
\hline 2020-05-01 & 35,043 & 0.032 & 0.002 & 0.049 & 0.002 & 0.058 & 0.002 & 0.004 \\
\hline $2020-05-10$ & 62,939 & 0.103 & 0.024 & 0.027 & 0.025 & 0.139 & 0.021 & 0.017 \\
\hline $2020-05-16$ & 85,940 & 0.201 & 0.021 & 0.396 & 0.020 & 0.177 & 0.015 & 0.016 \\
\hline
\end{tabular}


Fig. 4 Comparison of actual and estimated values of total cases

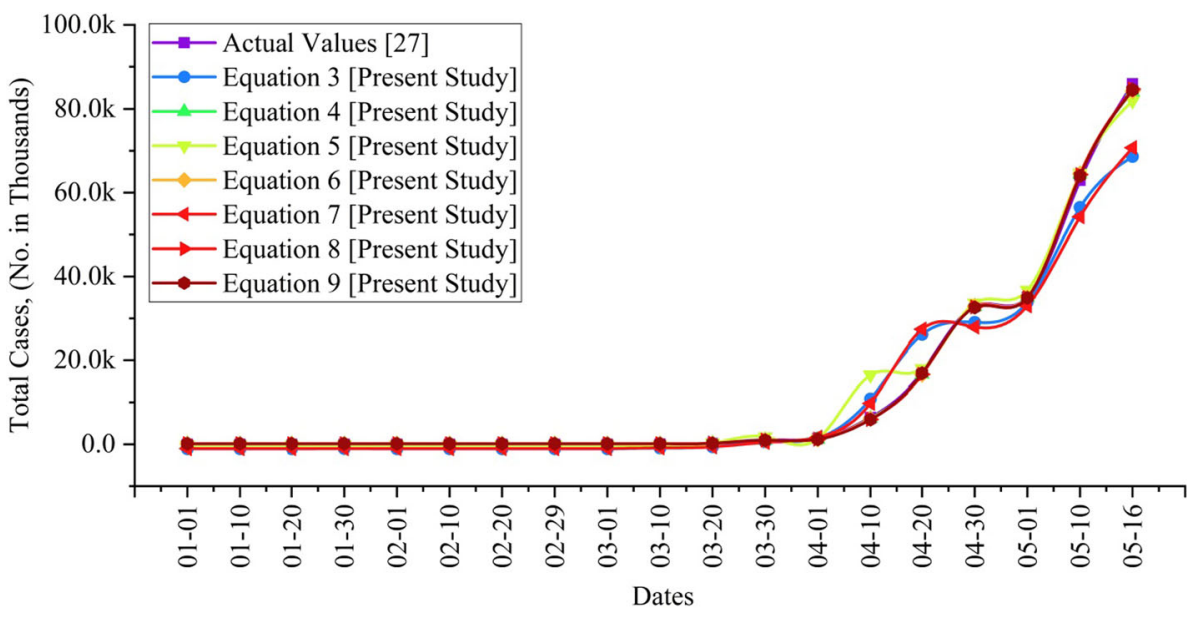

forecasted the GDP growth rate for 2020-21 for India at $2.1 \%$ when compared to China and USA as $1 \%$ and $-2.8 \%$ respectively [27, 28].

\section{Results and Discussion}

In this section, the results of statistical techniques applied in the present study are presented along with the interrelated recommendations for the improvement of GDP after COVID-19.

\section{Numerical Modeling}

Least-square approximation of linear regression technique has been utilized in the calculation of total cases of COVID-19 pandemic. The total cases can be calculated as a function of daily new cases, total deaths and daily new death's. Different regression equations are developed from the correlational analysis.

TotalCases $_{\text {Est. }}=f($ Dailynewcases, Totaldeaths, Dailynewdeaths $)$

For the analysis of COVID-19 statistical data of actual values of total cases, new cases, total deaths and new deaths are taken from WHO website from December 31, 2019 to May 16, 2020 [29]. Figure 3 illustrates the information of actual values of active cases and deaths due to COVID-19. To simplify the analysis, total deaths were measured in thousands and daily new deaths measured in numbers and dates were shown in step of ten days for simplicity. The total numbers of cases in India were less than 1100 up to March 30, 2020 and increased at an exponential rate after April 1, 2020 as shown in Fig. 3. Total cases are calculated by using seven different combinations; Carl Pearson coefficient $\left(\mathrm{R}^{2}\right)$ and constants obtained from the regression analysis are depicted in Table 2. The $\mathrm{R}^{2}$ value of the developed correlations is in the range of $85.71-95 \%$. The correlations developed by using single, two and three variables under considerations are shown below:

$$
\begin{aligned}
\text { TotalCases }_{E s t .}= & -1062+17.554 * \text { DailyNewCases } \\
\text { TotalCases }_{E s t .}= & 109.8+30.5211 * \text { TotalDeaths } \\
\text { TotalCases }_{E s t .}= & -225+506.5 * \text { DailyNewDeaths } \\
\text { TotalCases }_{E s t .}= & 126-0.177 * \text { DailyNewCases }+30.815 \\
& * \text { TotalDeaths }
\end{aligned}
$$

TotalCases $_{E s t .}=-1035+20.48 *$ DailyNewCases -92.7

$$
\text { * DailyNewDeaths }
$$

$$
\begin{aligned}
\text { TotalCases }_{\text {Est. }}= & 152.5+31.179 * \text { TotalDeaths }-12.68 \\
& * \text { DailyNewDeaths } \\
\text { TotalCases }_{\text {Est. }}= & 122+30.564 * \text { TotalDeaths }+0.584 \\
& * \text { DailyNewCases }-19.54 \\
& * \text { DailyNewDeaths }
\end{aligned}
$$

Table 3 illustrates the percentile error observed in estimated and actual values for the total cases. The highlighted cell shows the highest and the lowest percentile error given by the regressions correlations.

Figure 4 shows the estimated values obtained from the developed correlations compared with the actual total cases estimated by WHOs [25].

Minimum and maximum percentile observed in developed correlations ranges from 0.002 to 4.171 . These correlations can also be useful for predicting data at macrolevel (country and state) micro-level (district, cities, municipal corporation, villages, etc.). In the present study, 
the data set under consideration is from December 31, 2019 to May 16, 2020. However, the developed correlations are applied for predicting the total cases for May 17, 2020 with the deviation of $\pm 3 \%$.

\section{Remedies for Improving GDP}

Identifying the effective response strategies to fight against COVID-19 is very important. Eminent scientist, doctors and health officials are trying to identify preventive and treatment strategies to defeat COVID-19. Epidemiological modeling needs different approach as compare to engineering problem. The author believes that the present study will help the public health officials to handle COVID-19 problem which is unstable and open ended in nature. Principal of control theory involving feedback system can be applied to normalize the issue of COVID-19 with various approaches to manage trade-off between economy and health outcome. The International Monitory Fund (IMF) has cut the India's growth forecast for 2020-21 to $1.9 \%$ down from its earlier estimate of $5.8 \%$ in January this year. Also workers and members of lower income group have been hit hard as their wages disappeared. The International Labour Organization (ILO) estimates that 400 million peoples in India are at risk of sinking deeper into poverty [30]. There is a strong relationship between social, health, environment and economy. As India is trying to boost up its economy, exploring new resources of growth and identifying systematic actions are needed for sustainable economic growth. There are few interrelated recommendations to boost economy [31].

- Investment on cleaner production technologies.

- Application of virtual technology such as information communication technology (ICT) tools in all sectors.

- Online and digitization in various sectors.

- Relook and revamp to take into an account new drivers of growth in biotechnology and pharmaceuticals, renewable energy and organic farming.

- Expand excess to clean water and air.

- Application of fiscal mechanism.
- Promotion of self-sufficiency of economics in health, education, agriculture and communications.

\section{Limitations}

Limitations of our current work are as follows:

- Only linear relationship has been developed for the given data set.

- Present study is only applicable for Indian context.

- The study is limited to only short-term prediction.

\section{Conclusions}

COVID-19 has spread worldwide within a short span of time and affected a social and economic life of the human beings. WHO issued worldwide health emergency, indicating that SARs-CoV-2 is of urgent global concerned and estimated that reproduction factor $\left(\mathrm{R}_{0}\right)$ as 2.7. This research paper proposed a least-square approximation of linear regression technique for estimating the total cases of COVID-19 in India as a function of daily new cases, total deaths and daily new deaths. Seven correlations were developed to predict the total cases with the average accuracy of $96.65 \%$. This kind of study is capable of providing a predictive solution to current and future pandemics and can be useful for public health officials for taking better decisions. Due to interrelationship between social, health, environment and economy, the country is vulnerable to economic downturn and needs greater access to new sources of growth that will improve life expectancy and economy. In the future, the study will be enhanced by adding variables like temperature and oxygen level of the patients.

\section{Appendix}

See Fig. 5.

See Table 4. 


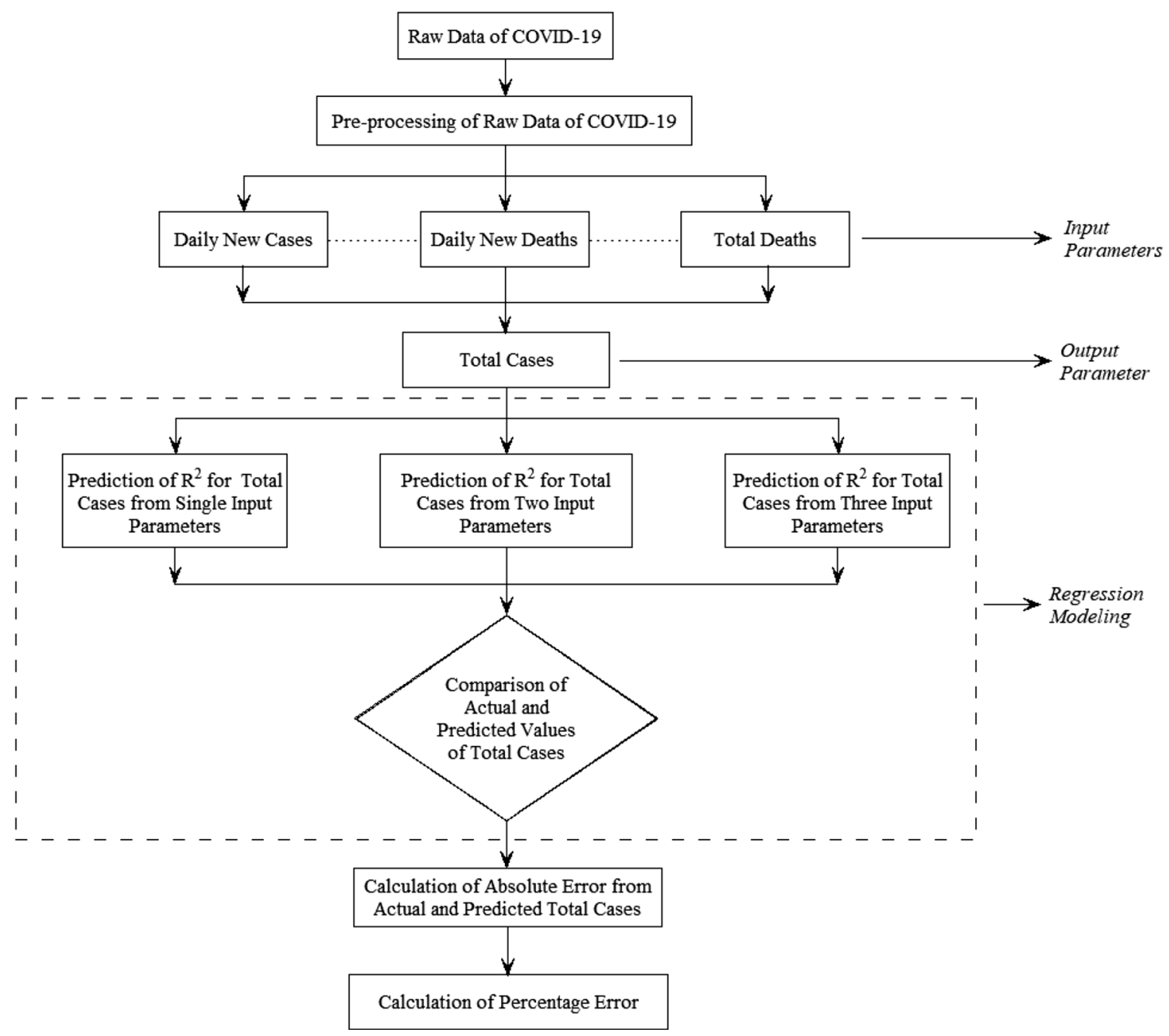

Fig. 5 Flow chart of modeling 
Table 4 Estimation of total cases through regression analysis and calculation of absolute error

\begin{tabular}{|c|c|c|c|c|c|c|c|c|c|c|c|c|c|c|}
\hline \multirow{2}{*}{$\begin{array}{l}\text { Actual } \\
\text { Total cases }\end{array}$} & \multicolumn{7}{|c|}{ Estimation of total cases through regression analysis } & \multicolumn{7}{|c|}{ Calculation of absolute error } \\
\hline & 3 & 4 & 5 & 6 & 7 & 8 & 9 & 3 & 4 & 5 & 6 & 7 & 8 & 9 \\
\hline 0 & -1062 & 110 & -225 & 126 & -1035 & 153 & 122 & 0.00 & 0.00 & 0.00 & 0.00 & 0.00 & 0.00 & 0.00 \\
\hline 0 & -1062 & 110 & -225 & 126 & -1035 & 153 & 122 & 0.00 & 0.00 & 0.00 & 0.00 & 0.00 & 0.00 & 0.00 \\
\hline 0 & -1062 & 110 & -225 & 126 & -1035 & 153 & 122 & 0.00 & 0.00 & 0.00 & 0.00 & 0.00 & 0.00 & 0.00 \\
\hline 0 & -1062 & 110 & -225 & 126 & -1035 & 153 & 122 & 0.00 & 0.00 & 0.00 & 0.00 & 0.00 & 0.00 & 0.00 \\
\hline 0 & -1062 & 110 & -225 & 126 & -1035 & 153 & 122 & 0.00 & 0.00 & 0.00 & 0.00 & 0.00 & 0.00 & 0.00 \\
\hline 0 & -1062 & 110 & -225 & 126 & -1035 & 153 & 122 & 0.00 & 0.00 & 0.00 & 0.00 & 0.00 & 0.00 & 0.00 \\
\hline 0 & -1062 & 110 & -225 & 126 & -1035 & 153 & 122 & 0.00 & 0.00 & 0.00 & 0.00 & 0.00 & 0.00 & 0.00 \\
\hline 0 & -1062 & 110 & -225 & 126 & -1035 & 153 & 122 & 0.00 & 0.00 & 0.00 & 0.00 & 0.00 & 0.00 & 0.00 \\
\hline 0 & -1062 & 110 & -225 & 126 & -1035 & 153 & 122 & 0.00 & 0.00 & 0.00 & 0.00 & 0.00 & 0.00 & 0.00 \\
\hline 0 & -1062 & 110 & -225 & 126 & -1035 & 153 & 122 & 0.00 & 0.00 & 0.00 & 0.00 & 0.00 & 0.00 & 0.00 \\
\hline 0 & -1062 & 110 & -225 & 126 & -1035 & 153 & 122 & 0.00 & 0.00 & 0.00 & 0.00 & 0.00 & 0.00 & 0.00 \\
\hline 0 & -1062 & 110 & -225 & 126 & -1035 & 153 & 122 & 0.00 & 0.00 & 0.00 & 0.00 & 0.00 & 0.00 & 0.00 \\
\hline 0 & -1062 & 110 & -225 & 126 & -1035 & 153 & 122 & 0.00 & 0.00 & 0.00 & 0.00 & 0.00 & 0.00 & 0.00 \\
\hline 0 & -1062 & 110 & -225 & 126 & -1035 & 153 & 122 & 0.00 & 0.00 & 0.00 & 0.00 & 0.00 & 0.00 & 0.00 \\
\hline 0 & -1062 & 110 & -225 & 126 & -1035 & 153 & 122 & 0.00 & 0.00 & 0.00 & 0.00 & 0.00 & 0.00 & 0.00 \\
\hline 0 & -1062 & 110 & -225 & 126 & -1035 & 153 & 122 & 0.00 & 0.00 & 0.00 & 0.00 & 0.00 & 0.00 & 0.00 \\
\hline 0 & -1062 & 110 & -225 & 126 & -1035 & 153 & 122 & 0.00 & 0.00 & 0.00 & 0.00 & 0.00 & 0.00 & 0.00 \\
\hline 0 & -1062 & 110 & -225 & 126 & -1035 & 153 & 122 & 0.00 & 0.00 & 0.00 & 0.00 & 0.00 & 0.00 & 0.00 \\
\hline 0 & -1062 & 110 & -225 & 126 & -1035 & 153 & 122 & 0.00 & 0.00 & 0.00 & 0.00 & 0.00 & 0.00 & 0.00 \\
\hline 0 & -1062 & 110 & -225 & 126 & -1035 & 153 & 122 & 0.00 & 0.00 & 0.00 & 0.00 & 0.00 & 0.00 & 0.00 \\
\hline 0 & -1062 & 110 & -225 & 126 & -1035 & 153 & 122 & 0.00 & 0.00 & 0.00 & 0.00 & 0.00 & 0.00 & 0.00 \\
\hline 0 & -1062 & 110 & -225 & 126 & -1035 & 153 & 122 & 0.00 & 0.00 & 0.00 & 0.00 & 0.00 & 0.00 & 0.00 \\
\hline 0 & -1062 & 110 & -225 & 126 & -1035 & 153 & 122 & 0.00 & 0.00 & 0.00 & 0.00 & 0.00 & 0.00 & 0.00 \\
\hline 0 & -1062 & 110 & -225 & 126 & -1035 & 153 & 122 & 0.00 & 0.00 & 0.00 & 0.00 & 0.00 & 0.00 & 0.00 \\
\hline 0 & -1062 & 110 & -225 & 126 & -1035 & 153 & 122 & 0.00 & 0.00 & 0.00 & 0.00 & 0.00 & 0.00 & 0.00 \\
\hline 0 & -1062 & 110 & -225 & 126 & -1035 & 153 & 122 & 0.00 & 0.00 & 0.00 & 0.00 & 0.00 & 0.00 & 0.00 \\
\hline 0 & -1062 & 110 & -225 & 126 & -1035 & 153 & 122 & 0.00 & 0.00 & 0.00 & 0.00 & 0.00 & 0.00 & 0.00 \\
\hline 0 & -1062 & 110 & -225 & 126 & -1035 & 153 & 122 & 0.00 & 0.00 & 0.00 & 0.00 & 0.00 & 0.00 & 0.00 \\
\hline 0 & -1062 & 110 & -225 & 126 & -1035 & 153 & 122 & 0.00 & 0.00 & 0.00 & 0.00 & 0.00 & 0.00 & 0.00 \\
\hline 0 & -1062 & 110 & -225 & 126 & -1035 & 153 & 122 & 0.00 & 0.00 & 0.00 & 0.00 & 0.00 & 0.00 & 0.00 \\
\hline 1 & -1044 & 110 & -225 & 126 & -1015 & 153 & 122 & 1045.45 & 108.80 & 226.00 & 124.82 & 1015.52 & 151.50 & 121.00 \\
\hline 1 & -1062 & 110 & -225 & 126 & -1035 & 153 & 122 & 1063.00 & 108.80 & 226.00 & 125.00 & 1036.00 & 151.50 & 121.00 \\
\hline 1 & -1062 & 110 & -225 & 126 & -1035 & 153 & 122 & 1063.00 & 108.80 & 226.00 & 125.00 & 1036.00 & 151.50 & 121.00 \\
\hline 2 & -1044 & 110 & -225 & 126 & -1015 & 153 & 122 & 523.22 & 53.90 & 113.50 & 61.91 & 508.26 & 75.25 & 60.00 \\
\hline 2 & -1062 & 110 & -225 & 126 & -1035 & 153 & 122 & 532.00 & 53.90 & 113.50 & 62.00 & 518.50 & 75.25 & 60.00 \\
\hline 3 & -1044 & 110 & -225 & 126 & -1015 & 153 & 122 & 349.15 & 35.60 & 76.00 & 40.94 & 339.17 & 49.83 & 39.67 \\
\hline 3 & -1062 & 110 & -225 & 126 & -1035 & 153 & 122 & 355.00 & 35.60 & 76.00 & 41.00 & 346.00 & 49.83 & 39.67 \\
\hline 3 & -1062 & 110 & -225 & 126 & -1035 & 153 & 122 & 355.00 & 35.60 & 76.00 & 41.00 & 346.00 & 49.83 & 39.67 \\
\hline 3 & -1062 & 110 & -225 & 126 & -1035 & 153 & 122 & 355.00 & 35.60 & 76.00 & 41.00 & 346.00 & 49.83 & 39.67 \\
\hline 3 & -1062 & 110 & -225 & 126 & -1035 & 153 & 122 & 355.00 & 35.60 & 76.00 & 41.00 & 346.00 & 49.83 & 39.67 \\
\hline 3 & -1062 & 110 & -225 & 126 & -1035 & 153 & 122 & 355.00 & 35.60 & 76.00 & 41.00 & 346.00 & 49.83 & 39.67 \\
\hline 3 & -1062 & 110 & -225 & 126 & -1035 & 153 & 122 & 355.00 & 35.60 & 76.00 & 41.00 & 346.00 & 49.83 & 39.67 \\
\hline 3 & -1062 & 110 & -225 & 126 & -1035 & 153 & 122 & 355.00 & 35.60 & 76.00 & 41.00 & 346.00 & 49.83 & 39.67 \\
\hline 3 & -1062 & 110 & -225 & 126 & -1035 & 153 & 122 & 355.00 & 35.60 & 76.00 & 41.00 & 346.00 & 49.83 & 39.67 \\
\hline 3 & -1062 & 110 & -225 & 126 & -1035 & 153 & 122 & 355.00 & 35.60 & 76.00 & 41.00 & 346.00 & 49.83 & 39.67 \\
\hline 3 & -1062 & 110 & -225 & 126 & -1035 & 153 & 122 & 355.00 & 35.60 & 76.00 & 41.00 & 346.00 & 49.83 & 39.67 \\
\hline
\end{tabular}


Table 4 continued

\begin{tabular}{|c|c|c|c|c|c|c|c|c|c|c|c|c|c|c|}
\hline \multirow{2}{*}{$\begin{array}{l}\text { Actual } \\
\text { Total cases }\end{array}$} & \multicolumn{7}{|c|}{ Estimation of total cases through regression analysis } & \multicolumn{7}{|c|}{ Calculation of absolute error } \\
\hline & 3 & 4 & 5 & 6 & 7 & 8 & 9 & 3 & 4 & 5 & 6 & 7 & 8 & 9 \\
\hline 3 & -1062 & 110 & -225 & 126 & -1035 & 153 & 122 & 355.00 & 35.60 & 76.00 & 41.00 & 346.00 & 49.83 & 39.67 \\
\hline 3 & -1062 & 110 & -225 & 126 & -1035 & 153 & 122 & 355.00 & 35.60 & 76.00 & 41.00 & 346.00 & 49.83 & 39.67 \\
\hline 3 & -1062 & 110 & -225 & 126 & -1035 & 153 & 122 & 355.00 & 35.60 & 76.00 & 41.00 & 346.00 & 49.83 & 39.67 \\
\hline 3 & -1062 & 110 & -225 & 126 & -1035 & 153 & 122 & 355.00 & 35.60 & 76.00 & 41.00 & 346.00 & 49.83 & 39.67 \\
\hline 3 & -1062 & 110 & -225 & 126 & -1035 & 153 & 122 & 355.00 & 35.60 & 76.00 & 41.00 & 346.00 & 49.83 & 39.67 \\
\hline 3 & -1062 & 110 & -225 & 126 & -1035 & 153 & 122 & 355.00 & 35.60 & 76.00 & 41.00 & 346.00 & 49.83 & 39.67 \\
\hline 3 & -1062 & 110 & -225 & 126 & -1035 & 153 & 122 & 355.00 & 35.60 & 76.00 & 41.00 & 346.00 & 49.83 & 39.67 \\
\hline 3 & -1062 & 110 & -225 & 126 & -1035 & 153 & 122 & 355.00 & 35.60 & 76.00 & 41.00 & 346.00 & 49.83 & 39.67 \\
\hline 3 & -1062 & 110 & -225 & 126 & -1035 & 153 & 122 & 355.00 & 35.60 & 76.00 & 41.00 & 346.00 & 49.83 & 39.67 \\
\hline 3 & -1062 & 110 & -225 & 126 & -1035 & 153 & 122 & 355.00 & 35.60 & 76.00 & 41.00 & 346.00 & 49.83 & 39.67 \\
\hline 3 & -1062 & 110 & -225 & 126 & -1035 & 153 & 122 & 355.00 & 35.60 & 76.00 & 41.00 & 346.00 & 49.83 & 39.67 \\
\hline 3 & -1062 & 110 & -225 & 126 & -1035 & 153 & 122 & 355.00 & 35.60 & 76.00 & 41.00 & 346.00 & 49.83 & 39.67 \\
\hline 3 & -1062 & 110 & -225 & 126 & -1035 & 153 & 122 & 355.00 & 35.60 & 76.00 & 41.00 & 346.00 & 49.83 & 39.67 \\
\hline 3 & -1062 & 110 & -225 & 126 & -1035 & 153 & 122 & 355.00 & 35.60 & 76.00 & 41.00 & 346.00 & 49.83 & 39.67 \\
\hline 3 & -1062 & 110 & -225 & 126 & -1035 & 153 & 122 & 355.00 & 35.60 & 76.00 & 41.00 & 346.00 & 49.83 & 39.67 \\
\hline 3 & -1062 & 110 & -225 & 126 & -1035 & 153 & 122 & 355.00 & 35.60 & 76.00 & 41.00 & 346.00 & 49.83 & 39.67 \\
\hline 3 & -1062 & 110 & -225 & 126 & -1035 & 153 & 122 & 355.00 & 35.60 & 76.00 & 41.00 & 346.00 & 49.83 & 39.67 \\
\hline 5 & -1027 & 110 & -225 & 126 & -994 & 153 & 122 & 206.38 & 20.96 & 46.00 & 24.13 & 199.81 & 29.50 & 23.40 \\
\hline 6 & -1044 & 110 & -225 & 126 & -1015 & 153 & 122 & 175.07 & 17.30 & 38.50 & 19.97 & 170.09 & 24.42 & 19.33 \\
\hline 28 & -676 & 110 & -225 & 122 & -584 & 153 & 122 & 25.14 & 2.92 & 9.04 & 3.36 & 21.87 & 4.45 & 3.36 \\
\hline 29 & -1044 & 110 & -225 & 126 & -1015 & 153 & 122 & 37.02 & 2.79 & 8.76 & 3.34 & 35.98 & 4.26 & 3.21 \\
\hline 31 & -1027 & 110 & -225 & 126 & -994 & 153 & 122 & 34.13 & 2.54 & 8.26 & 3.05 & 33.07 & 3.92 & 2.94 \\
\hline 34 & -1009 & 110 & -225 & 125 & -974 & 153 & 122 & 30.69 & 2.23 & 7.62 & 2.69 & 29.63 & 3.49 & 2.59 \\
\hline 44 & -886 & 110 & -225 & 124 & -830 & 153 & 122 & 21.15 & 1.50 & 6.11 & 1.82 & 19.87 & 2.47 & 1.77 \\
\hline 50 & -957 & 110 & -225 & 125 & -912 & 153 & 122 & 20.13 & 1.20 & 5.50 & 1.50 & 19.24 & 2.05 & 1.44 \\
\hline 73 & -658 & 110 & -225 & 122 & -564 & 153 & 122 & 10.02 & 0.50 & 4.08 & 0.67 & 8.73 & 1.09 & 0.67 \\
\hline 75 & -1027 & 140 & 282 & 156 & -1087 & 171 & 134 & 14.69 & 0.87 & 2.75 & 1.09 & 15.49 & 1.28 & 0.78 \\
\hline 83 & -922 & 171 & 282 & 186 & -964 & 202 & 164 & 12.10 & 1.06 & 2.39 & 1.24 & 12.61 & 1.44 & 0.98 \\
\hline 90 & -939 & 171 & -225 & 186 & -892 & 215 & 183 & 11.43 & 0.90 & 3.50 & 1.07 & 10.91 & 1.39 & 1.03 \\
\hline 93 & -1009 & 171 & -225 & 187 & -974 & 215 & 183 & 11.85 & 0.84 & 3.42 & 1.01 & 11.47 & 1.31 & 0.97 \\
\hline 125 & -500 & 201 & 282 & 213 & -472 & 233 & 195 & 5.00 & 0.61 & 1.25 & 0.70 & 4.78 & 0.87 & 0.56 \\
\hline 137 & -851 & 201 & -225 & 216 & -789 & 246 & 214 & 7.21 & 0.47 & 2.64 & 0.58 & 6.76 & 0.80 & 0.56 \\
\hline 165 & -570 & 201 & -225 & 213 & -462 & 246 & 214 & 4.46 & 0.22 & 2.36 & 0.29 & 3.80 & 0.49 & 0.30 \\
\hline 191 & -606 & 232 & 282 & 245 & -595 & 264 & 225 & 4.17 & 0.21 & 0.47 & 0.28 & 4.12 & 0.38 & 0.18 \\
\hline 231 & -360 & 232 & -225 & 242 & -216 & 277 & 244 & 2.56 & 0.00 & 1.97 & 0.05 & 1.93 & 0.20 & 0.06 \\
\hline 320 & 500 & 232 & -225 & 234 & 788 & 277 & 244 & 0.56 & 0.28 & 1.70 & 0.27 & 1.46 & 0.13 & 0.24 \\
\hline 439 & 1027 & 323 & 1295 & 321 & 1124 & 333 & 279 & 1.34 & 0.26 & 1.95 & 0.27 & 1.56 & 0.24 & 0.36 \\
\hline 492 & -132 & 384 & 788 & 394 & -135 & 408 & 359 & 1.27 & 0.22 & 0.60 & 0.20 & 1.27 & 0.17 & 0.27 \\
\hline 562 & 167 & 384 & -225 & 391 & 399 & 433 & 397 & 0.70 & 0.32 & 1.40 & 0.30 & 0.29 & 0.23 & 0.29 \\
\hline 649 & 465 & 507 & 1801 & 511 & 376 & 507 & 444 & 0.28 & 0.22 & 1.78 & 0.21 & 0.42 & 0.22 & 0.32 \\
\hline 724 & 255 & 629 & 1801 & 637 & 130 & 631 & 566 & 0.65 & 0.13 & 1.49 & 0.12 & 0.82 & 0.13 & 0.22 \\
\hline 873 & 1554 & 690 & 788 & 685 & 1831 & 719 & 665 & 0.78 & 0.21 & 0.10 & 0.22 & 1.10 & 0.18 & 0.24 \\
\hline 979 & 799 & 873 & 2814 & 878 & 580 & 855 & 772 & 0.18 & 0.11 & 1.87 & 0.10 & 0.41 & 0.13 & 0.21 \\
\hline 1071 & 553 & 995 & 1801 & 1003 & 478 & 1005 & 933 & 0.48 & 0.07 & 0.68 & 0.06 & 0.55 & 0.06 & 0.13 \\
\hline 1251 & 2098 & 1086 & 1295 & 1080 & 2373 & 1112 & 1043 & 0.68 & 0.13 & 0.03 & 0.14 & 0.90 & 0.11 & 0.17 \\
\hline 1397 & 1501 & 1178 & 1295 & 1179 & 1677 & 1205 & 1135 & 0.07 & 0.16 & 0.07 & 0.16 & 0.20 & 0.14 & 0.19 \\
\hline
\end{tabular}


Table 4 continued

\begin{tabular}{|c|c|c|c|c|c|c|c|c|c|c|c|c|c|c|}
\hline \multirow{2}{*}{$\begin{array}{l}\text { Actual } \\
\text { Total cases }\end{array}$} & \multicolumn{7}{|c|}{ Estimation of total cases through regression analysis } & \multicolumn{7}{|c|}{ Calculation of absolute error } \\
\hline & 3 & 4 & 5 & 6 & 7 & 8 & 9 & 3 & 4 & 5 & 6 & 7 & 8 & 9 \\
\hline 1965 & 8909 & 1636 & 7373 & 1566 & 9207 & 1520 & 1366 & 3.53 & 0.17 & 2.75 & 0.20 & 3.69 & 0.23 & 0.30 \\
\hline 2301 & 4836 & 1819 & 2814 & 1792 & 5290 & 1821 & 1720 & 1.10 & 0.21 & 0.22 & 0.22 & 1.30 & 0.21 & 0.25 \\
\hline 2902 & 9488 & 2185 & 5853 & 2115 & 10,161 & 2119 & 1973 & 2.27 & 0.25 & 1.02 & 0.27 & 2.50 & 0.27 & 0.32 \\
\hline 3374 & 7223 & 2460 & 4334 & 2415 & 7797 & 2438 & 2305 & 1.14 & 0.27 & 0.28 & 0.28 & 1.31 & 0.28 & 0.32 \\
\hline 4067 & 11,103 & 3437 & 15,983 & 3362 & 10,191 & 3143 & 2847 & 1.73 & 0.16 & 2.93 & 0.17 & 1.51 & 0.23 & 0.30 \\
\hline 4421 & 5152 & 3589 & 2308 & 3576 & 5751 & 3641 & 3512 & 0.17 & 0.19 & 0.48 & 0.19 & 0.30 & 0.18 & 0.21 \\
\hline 5194 & 12,507 & 4657 & 17,503 & 4581 & 11,552 & 4351 & 4013 & 1.41 & 0.10 & 2.37 & 0.12 & 1.22 & 0.16 & 0.23 \\
\hline 5734 & 8417 & 5176 & 8386 & 5146 & 8448 & 5109 & 4873 & 0.47 & 0.10 & 0.46 & 0.10 & 0.47 & 0.11 & 0.15 \\
\hline 6412 & 10,840 & 6183 & 16,490 & 6138 & 9791 & 5935 & 5579 & 0.69 & 0.04 & 1.57 & 0.04 & 0.53 & 0.07 & 0.13 \\
\hline 7447 & 17,106 & 7404 & 20,035 & 7308 & 16,454 & 7092 & 6669 & 1.30 & 0.01 & 1.69 & 0.02 & 1.21 & 0.05 & 0.10 \\
\hline 8356 & 14,895 & 8442 & 16,996 & 8378 & 14,430 & 8228 & 7821 & 0.78 & 0.01 & 1.03 & 0.00 & 0.73 & 0.02 & 0.06 \\
\hline 9152 & 12,911 & 9510 & 17,503 & 9476 & 12,023 & 9306 & 8872 & 0.41 & 0.04 & 0.91 & 0.04 & 0.31 & 0.02 & 0.03 \\
\hline 10,363 & 20,196 & 10,456 & 15,477 & 10,358 & 20,893 & 10,322 & 9896 & 0.95 & 0.01 & 0.49 & 0.00 & 1.02 & 0.00 & 0.05 \\
\hline 11,438 & 17,809 & 11,616 & 19,022 & 11,553 & 17,458 & 11,418 & 10,924 & 0.56 & 0.02 & 0.66 & 0.01 & 0.53 & 0.00 & 0.04 \\
\hline 12,380 & 15,474 & 12,746 & 18,516 & 12,717 & 14,827 & 12,583 & 12,074 & 0.25 & 0.03 & 0.50 & 0.03 & 0.20 & 0.02 & 0.02 \\
\hline 13,387 & 16,615 & 13,448 & 11,425 & 13,414 & 17,456 & 13,477 & 13,042 & 0.24 & 0.00 & 0.15 & 0.00 & 0.30 & 0.01 & 0.03 \\
\hline 14,378 & 16,334 & 14,760 & 21,555 & 14,742 & 15,275 & 14,564 & 13,978 & 0.14 & 0.03 & 0.50 & 0.03 & 0.06 & 0.01 & 0.03 \\
\hline 15,712 & 22,355 & 15,584 & 13,451 & 15,513 & 23,782 & 15,608 & 15,106 & 0.42 & 0.01 & 0.14 & 0.01 & 0.51 & 0.01 & 0.04 \\
\hline 17,265 & 26,199 & 16,683 & 18,009 & 16,584 & 27,433 & 16,615 & 16,036 & 0.52 & 0.03 & 0.04 & 0.04 & 0.59 & 0.04 & 0.07 \\
\hline 18,600 & 22,373 & 18,117 & 23,581 & 18,071 & 21,949 & 17,940 & 17,264 & 0.20 & 0.03 & 0.27 & 0.03 & 0.18 & 0.04 & 0.07 \\
\hline 19,984 & 23,233 & 19,643 & 25,100 & 19,603 & 22,674 & 19,460 & 18,735 & 0.16 & 0.02 & 0.26 & 0.02 & 0.13 & 0.03 & 0.06 \\
\hline 21,393 & 23,672 & 20,895 & 20,542 & 20,862 & 24,021 & 20,852 & 20,159 & 0.11 & 0.02 & 0.04 & 0.02 & 0.12 & 0.03 & 0.06 \\
\hline 23,077 & 28,499 & 22,024 & 18,516 & 21,953 & 30,023 & 22,056 & 21,366 & 0.23 & 0.05 & 0.20 & 0.05 & 0.30 & 0.04 & 0.07 \\
\hline 24,506 & 24,023 & 23,764 & 28,646 & 23,755 & 22,947 & 23,578 & 22,729 & 0.02 & 0.03 & 0.17 & 0.03 & 0.06 & 0.04 & 0.07 \\
\hline 26,496 & 33,870 & 25,259 & 24,594 & 25,165 & 35,178 & 25,206 & 24,378 & 0.28 & 0.05 & 0.07 & 0.05 & 0.33 & 0.05 & 0.08 \\
\hline 27,892 & 23,443 & 26,724 & 24,087 & 26,750 & 23,105 & 26,715 & 25,864 & 0.16 & 0.04 & 0.14 & 0.04 & 0.17 & 0.04 & 0.07 \\
\hline 29,435 & 26,024 & 28,617 & 31,178 & 28,634 & 24,818 & 28,469 & 27,494 & 0.12 & 0.03 & 0.06 & 0.03 & 0.16 & 0.03 & 0.07 \\
\hline 31,332 & 32,238 & 30,845 & 36,750 & 30,821 & 31,048 & 30,604 & 29,516 & 0.03 & 0.02 & 0.17 & 0.02 & 0.01 & 0.02 & 0.06 \\
\hline 33,050 & 29,096 & 32,889 & 33,711 & 32,917 & 27,939 & 32,768 & 31,678 & -0.12 & 0.00 & 0.02 & 0.00 & 0.15 & 0.01 & 0.04 \\
\hline 35,043 & 33,923 & 35,118 & 36,750 & 35,118 & 33,015 & 34,966 & 33,795 & -0.03 & 0.00 & 0.05 & 0.00 & 0.06 & 0.00 & 0.04 \\
\hline 37,336 & 39,189 & 37,284 & 35,737 & 37,253 & 39,344 & 37,204 & 36,003 & 0.05 & 0.00 & 0.04 & 0.00 & 0.05 & 0.00 & 0.04 \\
\hline 39,980 & 45,351 & 39,818 & 41,815 & 39,748 & 45,420 & 39,638 & 38,312 & 0.13 & 0.00 & 0.05 & 0.01 & 0.14 & 0.01 & 0.04 \\
\hline 42,533 & 43,753 & 42,015 & 36,243 & 41,983 & 44,576 & 42,021 & 40,722 & 0.03 & 0.01 & 0.15 & 0.01 & 0.05 & 0.01 & 0.04 \\
\hline 46,433 & 67,399 & 47,967 & 98,543 & 47,754 & 60,761 & 46,537 & 44,350 & 0.45 & 0.03 & 1.12 & 0.03 & 0.31 & 0.00 & 0.04 \\
\hline 49,391 & 50,863 & 51,813 & 63,594 & 51,803 & 47,865 & 51,338 & 49,509 & 0.03 & 0.05 & 0.29 & 0.05 & 0.03 & 0.04 & 0.00 \\
\hline 52,952 & 61,448 & 54,529 & 44,854 & 54,439 & 63,644 & 54,580 & 52,931 & 0.16 & 0.03 & 0.15 & 0.03 & 0.20 & 0.03 & 0.00 \\
\hline 56,342 & 58,446 & 57,673 & 51,945 & 57,643 & 58,844 & 57,612 & 55,813 & 0.04 & 0.02 & 0.08 & 0.02 & 0.04 & 0.02 & 0.01 \\
\hline 59,662 & 57,217 & 60,572 & 47,893 & 60,583 & 58,152 & 60,674 & 58,868 & 0.04 & 0.02 & 0.20 & 0.02 & 0.03 & 0.02 & 0.01 \\
\hline 62,939 & 56,462 & 64,479 & 64,607 & 64,535 & 54,212 & 64,244 & 62,155 & 0.10 & 0.02 & 0.03 & 0.03 & 0.14 & 0.02 & 0.01 \\
\hline 67,152 & 72,893 & 67,439 & 48,906 & 67,358 & 76,255 & 67,659 & 65,707 & 0.09 & 0.00 & 0.27 & 0.00 & 0.14 & 0.01 & 0.02 \\
\hline 70,756 & 62,203 & 70,095 & 43,841 & 70,147 & 64,710 & 70,497 & 68,556 & 0.12 & 0.01 & 0.38 & 0.01 & 0.09 & 0.00 & 0.03 \\
\hline 74,281 & 60,816 & 73,818 & 61,568 & 73,920 & 59,848 & 73,855 & 71,621 & 0.18 & 0.01 & 0.17 & 0.00 & 0.19 & 0.01 & 0.04 \\
\hline 78,003 & 64,274 & 77,908 & 67,646 & 78,015 & 62,770 & 77,878 & 75,490 & 0.18 & 0.00 & 0.13 & 0.00 & 0.20 & 0.00 & 0.03 \\
\hline 81,970 & 68,575 & 80,960 & 50,425 & 81,053 & 70,939 & 81,425 & 79,190 & 0.16 & 0.01 & 0.38 & 0.01 & 0.13 & 0.01 & 0.03 \\
\hline 85,940 & 68,627 & 84,104 & 51,945 & 84,226 & 70,723 & 84,596 & 82,282 & 0.20 & 0.02 & 0.40 & 0.02 & 0.18 & 0.02 & 0.04 \\
\hline
\end{tabular}




\section{References}

1. I. Abdeljaoued-Tej, COVID-19 data analysis and modeling in Palestine. medRxiv 9(3), 50 (2020)

2. T. Chakraborty, I. Ghosh, Real-time forecasts and risk assessment of novel coronavirus (COVID-19) cases: a data-driven analysis. Chaos Solitons Fractals 135, 109850 (2020)

3. K. Chatterjee, K. Chatterjee, A. Kumar, S. Shankar, Healthcare impact of COVID-19 epidemic in India: a stochastic mathematical model. Med. J. Armed Forces India 76(2), 147-155 (2020)

4. P. Chatterjee, Indian pharma threatened by COVID-19 shutdowns in China. The Lancet 395(10225), 675 (2020)

5. N. Chintalapudi, G. Battineni, F. Amenta, COVID-19 disease outbreak forecasting of registered and recovered cases after sixty day lockdown in Italy: a data driven model approach. J. Microbiol. Immunol. Infect. 53(3), 396-403 (2020)

6. H.G. Garcell, COVID-19. Un reto para los profesionales de la salud. Revista Habanera de Ciencias Médicas 19(2), 3284 (2020)

7. Q. Li, W. Feng, Y.H. Quan, Trend and forecasting of the COVID19 outbreak in China. J. Infect. 80(4), 469-496 (2020)

8. R. Li, S. Qiao, G. Zhang, Analysis of angiotensin-converting enzyme 2 (ACE2) from different species sheds some light on cross-species receptor usage of a novel coronavirus 2019-nCoV. J. Infect. 80(4), 469-496 (2020)

9. Y.S. Long, Z. M. Zhai, L.L. Han, J. Kang, Y.L. Li, Z.H. Lin, Z. Liu, Quantitative assessment of the role of undocumented infection in the 2019 novel coronavirus (COVID-19) pandemic. arXiv preprint (2020). https://arxiv.org/abs/2003.12028

10. S. Mittal, An exploratory data analysis of COVID-19 in India. Int. J. Eng. Res. Technol. (IJERT) (2020). https://doi.org/10.17 577/IJERTV9IS040550

11. G. Pandey, P. Chaudhary, R. Gupta, S. Pal (2020). SEIR and regression model based COVID-19 outbreak predictions in India. arXiv preprint https://arxiv.org/abs/2004.00958

12. M. Perc, N. Gorišek Miksić, M. Slavinec, A. Stožer, Forecasting Covid-19. Front. Phys. 8, 127 (2020)

13. F. Petropoulos, S. Makridakis, Forecasting the novel coronavirus COVID-19. PLoS ONE 15(3), e0231236 (2020)

14. R. Singh, R. Adhikari, Age-structured impact of social distancing on the COVID-19 epidemic in India. arXiv preprint (2020). https://arxiv.org/abs/2003.12055

15. T. Singhal, A review of coronavirus disease-2019 (COVID-19). Indian J. Pediatr. 87(4), 281-286 (2020)
16. https://www.who.int/news-room/detail/27-04-2020-who-time line-covid-19 Date 16 May 2020 IST 3.33 pm

17. C.N. Van Dijk, Covid-19. J. ISAKOS 5(3), 115-116 (2020)

18. S. Zhang, M. Diao, W. Yu, L. Pei, Z. Lin, D. Chen, Estimation of the reproductive number of novel coronavirus (COVID-19) and the probable outbreak size on the Diamond Princess cruise ship: a data-driven analysis. Int. J. Infect. Dis. 93, 201-204 (2020)

19. P. Deprez, P.V. Shevchenko, M.V. Wüthrich, Machine learning techniques for mortality modeling. Eur. Actuar. J. 7(2), 337-352 (2017)

20. D. Hainaut, A neural-network analyzer for mortality forecast. ASTIN Bull. J. IAA 48(2), 481-508 (2018)

21. R. Richman, M.V. Wüthrich, A neural network extension of the Lee-Carter model to multiple populations. Ann. Actuar. Sci. 7, $1-21(2018)$

22. M. Ebden (2008). Gaussian processes for regression: a quick introduction. [online] Available at: $<$ http://www.robots.ox.ac.uk/ $\sim$ mebden/reports. GPtutorial. pdf

23. A. Khamparia, A. Singh, D. Anand, D. Gupta, A. Khanna, N.A. Kumar, J. Tan, A novel deep learning-based multi-model ensemble method for the prediction of neuromuscular disorders. Neural Comput. Appl. 32(15), 11083-11095 (2018)

24. S. Karthick, K.S. Kumar, S. Mohan, Relative analysis of controller effectiveness for vertical plane control of an autonomous underwater vehicle. OCEANS 2016 -Shanghai IEEE (2016). https://doi.org/10.1109/OCEANSAP.2016.7485569

25. http://statisticstimes.com/economy/projected-world-gdp-rank ing.php Date: 16 May 2020 IST 12.10 am

26. https://www.imf.org/en/About/Factsheets/IMF-at-a-Glance Date 16 May 2020 IST 6.08 pm

27. https://en.wikipedia.org/wiki/Social_impact_of_the_COVID-19_ pandemic Date: 16 May 2020 IST 12.13 am

28. https://www.india-briefing.com

29. https://ourworldindata.org/coronavirus-source-data date: 16 May 2020 IST $12.04 \mathrm{am}$

30. https://www.wri.org/blog/2020/04/after-covid-19-5-ways-indiacan-pursue-sustainable-and-resilient-recovery Date: 26 October 2020 IST 4.27 pm

31 .

https://www.livescience.com/worst-epidemics-and-pandemicsin-history.html Date 16 May 2020 IST 5.50 pm

Publisher's Note Springer Nature remains neutral with regard to jurisdictional claims in published maps and institutional affiliations. 